\title{
"MACHADO DE ASSIS, HOMEM DE AÇÃO", "A HUMANIDADE DE MACHADO DE ASSIS" E "MACHADO DE ASSIS VIVIA AS INQUIETAÇÕES DE SUA ÉPOCA"
}

\section{AUSTREGÉSILO DE ATHAYDE}

Academia Brasileira de Letras

Rio de Janeiro, Rio de Janeiro, Brasil

\section{APRESENTAÇÃO DE MARCELO DIEGO \\ Universidade Federal do Rio de Janeiro \\ Rio de Janeiro, Rio de Janeiro, Brasil}

Resumo: Reproduzem-se aqui três textos curtos de Austregésilo de Athayde sobre Machado de Assis, publicados originalmente na imprensa. Em "Machado de Assis, homem de ação", de 1939, o crítico interroga-se sobre a possibilidade de o escritor servir de modelo à juventude; em " A humanidade de Machado de Assis", de 1955, ele toma como ponto de partida para suas reflexões o livro Machado de Assis desconhecido, de Magalhães Júnior; e na entrevista "Machado de Assis vivia as inquietações de sua época", de 1958, observa a centralidade do Bruxo do Cosme Velho no sistema literário brasileiro.

Palavras-chave: Academia Brasileira de Letras; Comissão Machado de Assis; Magalhães Júnior.

\section{"MACHADO DE ASSIS, MAN OF ACTION", "THE HUMANITY OF MACHADO DE ASSIS" AND "MACHADO DE ASSIS EXPERIENCED THE CONCERNS OF HIS TIME"}

Abstract: This text includes three short texts about Machado de Assis by Austregésilo de Athayde, originally published in the daily press. In "Machado de Assis, Man of Action", from 1939, the critic asks himself whether the writer could be a role model for the youth; in "The Humanity of Machado de Assis", from 1955, the author bases his considerations on The Unknown Machado de Assis, by Magalhães Júnior; and in the interview "Machado de Assis Experienced the Concerns of His Time", from 1958, he observes the centrality of "the Wizard of Cosme Velho" in the Brazilian literary system.

Keywords: Brazilian Academy of Letters; Machado de Assis Comission; Magalhães Júnior. 


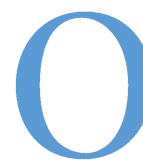

nome de Austregésilo de Athayde costuma ser associado ao de Machado de Assis principalmente por duas razões. A primeira é que, se foi Machado quem fundou a Academia Brasileira de Letras, pode-se dizer que Athayde foi quem a construiu: foi seu mais longevo presidente - por quase 35 anos, de 1959 a 1993 - e o responsável pela concepção e pela concretização do edifício-sede da instituição, anexo ao Petit Trianon, inaugurado em 1979 e que merecidamente leva o seu nome. Conforme se lê no perfil do intelectual que consta na página eletrônica da própria entidade,

[à] frente dos destinos da Academia, consagrou-se como o consolidador, o grande realizador, permanentemente devotado à tarefa de engrandecê-la espiritual e materialmente. A Academia tornou-se o centro de sua vida e ele converteu-se, com o passar do tempo, na própria encarnação da $\mathrm{ABL}$, transfundindo-se na Instituição que tão bem dirigiu. [...] (ACADEMIA BRASILEIRA DE LETRAS, online)

A segunda razão é ter sido ele um dos idealizadores da Comissão Machado de Assis, instituída por portaria de 19 de setembro de 1958 do Ministério da Educação e Cultura, e seu presidente a partir de 1959. A constituição da Comissão, de que eram membros natos os presidentes da Academia Brasileira de Letras, representante da sociedade civil, e do Instituto Nacional do livro, órgão do Governo Federal, e de que foram membros efetivos intelectuais brasileiros de primeira linha ao seu tempo, no campo da língua e da literatura (como Antônio Houaiss, Astrojildo Pereira, Aurélio Buarque de Hollanda Ferreira, Celso Cunha, Eugênio Gomes, Francisco de Assis Barbosa, Barreto Filho, Galante de Sousa, Lúcia Miguel Pereira e Magalhães Júnior), atendia à necessidade - ou à expectativa - de fixação de um "texto definitivo" da obra do escritor, uma vez que ela havia caído em domínio público naquele mesmo mês, quando se completaram cinquenta anos da morte do Bruxo do Cosme Velho. Em artigo intitulado "A Comissão Machado de Assis e a crítica textual no Brasil", José Pereira da Silva comenta:

[F]oi a primeira equipe brasileira de significativa importância que tratou teórica e praticamente a questão da edição crítica no Brasil e ainda é a base para o desenvolvimento da técnica da edição crítica de textos modernos com objetivos linguísticos, filológicos e literários. (SILVA, p. 6) 
O próprio Athayde confessaria, mais tarde, que desde muito cedo acalentara o sonho da criação de um espaço específico destinado à pesquisa machadiana. Na crônica "O presidente Machado de Assis", comentando a segunda edição do livro O presidente Machado de Assis, de Josué Montello, em 1986, ele declara:

A geração imediata à de Machado de Assis deu início ao processo crítico do artista e do homem, investigando-lhe a obra e a vida. Fê-lo ainda sob a impressão das opiniões dominantes e sem a objetividade que a documentação posterior permitiu a investigadores tenazes e armados de métodos científicos mais seguros.

O livro de Alfredo Pujol, com uma série de conferência sobre Machado, foi, por muito tempo, o melhor roteiro para os que buscavam conhecer o homem e o escritor. O pequeno ensaio de Alcides Maya e a biografia de Lúcia Miguel Pereira abriram perspectivas mais novas para uma outra compreensão do valor do artista.

Somente nos últimos quinze anos é que um grupo mais bem aparelhado de estudiosos de Machado começou a realizar o trabalho que eu propunha em 1921, num artigo publicado no Correio da Manhã, com a fundação de um centro de pesquisas do mundo complexo e, sob tantos aspectos hoje, também misterioso da criação machadiana. (ATHAYDE, 2008, p. 190)

Contudo, não foi apenas por meio de sua atuação institucional que Athayde celebrou o legado machadiano. Ao longo das oito décadas durante as quais contribuiu quase diariamente para a imprensa, ele também frequentou e discutiu, como crítico, a obra do escritor, em um número vasto de artigos, dispersos em periódicos variados. Nascido em 25 de setembro de 1898, em Caruaru, Pernambuco, Belarmino Maria Austregésilo Augusto de Athayde foi professor, jornalista, cronista, ensaísta e orador. Foi durante muito tempo a alma dos Diários Associados, de Assis Chateaubriand, no Rio de Janeiro, tendo desempenhado as funções de redator principal de $O$ jornal e de articulista e diretor de redação do Diário da Noite. Em 1948, foi enviado como delegado do Brasil à III Assembleia da Organização das Nações Unidas, em Paris, e feito membro da comissão que redigiu a Declaração Universal dos Direitos do Homem. Seus próprios companheiros o reconheceram como membro mais atuante dentro da comissão e mais diretamente responsável pela redação do documento - tanto que, passados vinte anos, quando o jurista e filósofo francês René Cassin, que também 
havia integrado a comissão, recebeu o Prêmio Nobel da Paz, em 1968, este fez questão de declarar, em seu discurso, que Athayde era igualmente merecedor da honraria. Eleito para a Academia Brasileira de Letras em 1951, faleceu no Rio de Janeiro, em 13 de setembro de 1993.

A seguir, a Machado de Assis em linha apresenta, por meio de três artigos, uma breve amostragem da reflexão de Austregésilo de Athayde sobre Machado de Assis. O primeiro artigo, de 1939, situa-se no bojo das comemorações do centenário de nascimento do escritor; o segundo, de 1955, é um comentário sobre o livro de Magalhães Júnior, Machado de Assis desconhecido, e já antecipa muitas das questões que se fariam presentes, poucos anos depois, a propósito do cinquentenário de morte do autor de Dom Casmurro; por fim, o terceiro localiza-se inteiramente em meio às celebrações desse cinquentenário. Assim, a amostragem selecionada, enquanto breve, cumpre sua função de panorama, ao flagrar o pensamento de Athayde sobre Machado em momentos bastante distintos de sua produção intelectual. Ademais, os três artigos revelam-se atualíssimos, na medida em que se insurgem contra aqueles que eram os lugares-comuns dos tempos em que foram escritos, em que não se submetem a modismos teóricos, nem subestimam em qualquer medida o texto e a pessoa de Machado de Assis.

Machado de Assis em linha presta, deste modo, sua homenagem a essa grande machadiano, agradecendo aos seus herdeiros, na pessoa de sua filha, Laura Austregésilo de Athayde Sandroni, pela autorização para publicação dos textos que se seguem.

\section{Machado de Assis, homem de ação}

Diário da Noite, Rio de Janeiro, 21 de junho de 1939, p. 2.

Propôs-se a questão de saber se Machado de Assis pode servir de modelo à juventude. Se na sua vida e na sua obra colheriam os moços, pelo exemplo e pelo ensinamento, com que se armarem de forças para a conquista dos ideais que os homens, ainda mais alheados das coisas do espírito, entretêm com amor, no começo da existência.

Houve quem o condenasse por dissolvente, se não dos costumes, pelo menos daquela coragem interior necessária a vencer os obstáculos e ir por diante. Que, sendo cético, não serviria para dar entusiasmo aos que precisam desse estímulo. Fixaram a sua psicologia num modelo de descrença, renúncia e mórbida contemplação. 
Eis que não concordo com isso. Machado de Assis foi um dos homens de ação do Brasil.

A ação não se revela tão somente pelo movimento, pela capacidade de construir, reformar, pregar ou comandar. Homens de ação não são apenas os que governam os povos, fazem revoluções, dirigem exércitos e criam interesses materiais ou do espírito. São também os que concebem ideias, coordenam sistemas, abrem na mesa do filósofo ou do artista novas perspectivas para a vida.

Todas as grandes transformações da sociedade moderna ligam-se a três pensadores tranquilos, que, ao semearem os seus princípios e concepções, estavam muito longe de supor, como os enciclopedistas, que seriam autores de sangrentas revoluções e inspiradores de uma era de violência no mundo.

Marx, o conde de Gobineau e Gustave le Bon não seriam homens de ação, no sentido estrito em que usualmente os limitam e definem. Mas o comunismo, o fascismo e o nazismo vêm das suas lições.

Há mais ação no Código Napoleônico do que nas batalhas de Austerlitz ou Marengo, na campanha da Itália ou do Egito. Há mais ação no Sermão da Montanha do que nas viagens do apóstolo São Paulo, para converter o gentio.

O pensamento, falado ou escrito, é, às vezes, fonte de uma ação perene, de repercussões incalculáveis nos destinos dos indivíduos e dos povos.

$$
* * *
$$

Machado de Assis nasceu no morro do Livramento, de um casal humílimo. O pai ocupava-se de pintura de casas e a mãe aumentava as rendas da família, trabalhando como empregada doméstica.

Veio das derradeiras camadas da sociedade e delas partiu para atingir a glória mais pura, detendo o inconteste primado na literatura da sua pátria. Durante cinquenta anos foi talvez o homem de mais ação no Brasil, embora outros houvesse de renome nas artes do governo, da guerra, da indústria ou do comércio, que ao tempo se agitaram em obras efêmeras.

Que esplêndida construção a dessa vida, que se iniciou na extrema humildade e se coroou da admiração dos povos civilizados!

O mestre foi por excelência um criador de tipos que vêm convivendo com tantas gerações, porque foram feitos da essência imortal da arte. E que ação é mais eficiente e bela, que a de dar vida a entes imorredouros? Quem 
trocaria, por exemplo, a glória de haver criado o Hamlet, o rei Lear, Cordélia ou Otelo, pelo comando da mais renhida batalha do mundo?

$$
* * *
$$

Sustento, pois, em paradoxo, que Machado de Assis foi um extraordinário homem de ação. E se não bastassem os seus quarenta livros para prová-lo, se não chegassem as vidas que nasceram da sua fantasia, aí está o exemplo da sua existência, a obra da sua conquista pessoal na sociedade, o esplendor da sua carreira.

Cidadão de memorável correção, dos que mais trabalharam pelo engrandecimento intelectual do Brasil, foi um patriota digno da admiração e do respeito da posteridade.

Funcionário e chefe de família sem cotejo, pela noção quase heroica que possuía dos seus deveres, ainda aí a juventude poderá encontrar no mestre um padrão de dignidade, que o coloca entre os varões mais ilustres e fecundos, que enobrecem a galeria dos nossos grandes homens.

\section{A humanidade de Machado de Assis}

O Cruzeiro, Rio de Janeiro, ano 27, n. 32, 21 de maio de 1955, p. 18.

O Sr. Raimundo Magalhães Júnior fez longo trabalho de pesquisa e produziu um livro original a respeito de Machado e Assis. Os muitos que já existem repetem a figura convencional do escritor: o homem frio, grave, distante. Um homem alheio aos movimentos políticos e sociais do seu tempo, esquivo no trato com os outros homens. Um Machado desumano, feito sob o modelo de Dom Casmurro, secarrão e inacessível. Um Machado que achava "derramados" aqueles que lhe falavam com expansão e alegria. Mais um burocrata hermético do que um analista associado às debilidades e grandezas da vida. O Sr. Magalhães Júnior não se conformou com o retrato habitual das biografias de Machado. Foi aos papéis antigos, releu jornais e revistas do tempo e buscou os novos traços da fisionomia espiritual do escritor fora dos seus livros. Há um mundo de crônicas, de sueltos, de artigos e até de contos, esparsos na imprensa, que não foram examinados pelos que já nos haviam contado a história da vida de Machado. Magalhães Júnior não se limitou a retocar o retrato. Na verdade, dá-nos um homem novo. Machado não viveu retraído dos acontecimentos do tempo, como tanto se tem escrito. Foi abolicionista, vibrou com as grandes vozes dos apóstolos da libertação. Acompanhava, com interesse, participando deles, pela paixão que suscitavam, os fatos políticos da época. Debatia-os com o calor do jornalista, 
opinava sem rebuço nem timidez. Era um homem feito da mesma massa de que os outros homens são feitos. Prestou Magalhães Júnior grande serviço às letras e maior ainda à memória de Machado, fixando-lhe a humanidade que lhe foi quase roubada por aqueles que se contentavam em ver apenas os aspectos formais do artista, pintado de preferência com as tintas e as cores com que ele mesmo pintara as suas personagens. Machado de Assis desconhecido é o título do livro, e o título corresponde ao esforço das revelações que encerra. Até a foto da capa não é a dura carantonha estereotipada no bronze, mas o rosto de um velhote sonhador, tocado de lirismo e bondade, como o Conselheiro Aires.

\section{Machado de Assis vivia as inquietações de sua época}

O Globo, Rio de Janeiro, 25 de setembro de 1958, p. 11.

Continuando a série de entrevistas sobre Machado de Assis, ao ensejo do cinquentenário de sua morte, a reportagem ouviu o acadêmico e jornalista Austregésilo de Ataíde. Disse-nos ele:

- Machado de Assis é membro da família intelectual que mais impressionou o meu espírito, no período de formação. No prefácio das Histórias amargas, livro escrito aos meus dezenove anos, Coelho Neto observou esta influência, afirmando mesmo: "[...] e à medida que as folheava, como que nelas sentia trescalar um perfume muito meu conhecido e na minha memória levantava-se, em sugestões, uma lembrança - direi melhor saudade - que, pouco a pouco, se foi definindo até que nela reconheci a 'maneira' ou 'arte' do grande Machado de Assis. O aroma de uma flor pode recordar-nos a floresta e foi em tal proporção que os seus contos evocaram, para mim, o espírito singularíssimo do escritor profundo, cujos passos o meu amigo vai rastreando e corajosamente, porque é preciso ter fôlego largo e olhar sutil para acompanhá-lo. Dizem que não deixou alunos. Insista o meu amigo em segui-lo e desmentirá tais vozes. Tente e, com seu triunfo, provará que alguém pode ser profeta em sua terra, e esse alguém será, no caso, o seu patrício Coelho Neto."

\section{Culto absorvente}

- Lembro isso, um pouco sem modéstia, apenas para dizer o quanto sou ligado à obra machadiana. Já soube de cor o conto "Missa do galo", o delírio de Brás Cubas e trechos daquela página imorredoura, "O velho Senado", sempre associado no meu espírito a "A última corrida de touros em 
Salvaterra", de Rebelo da Silva, embora sejam de assuntos tão diversos. Contudo, considero agora que existe um mundo culto muito absorvente de Machado de Assis em prejuízo, senão da glória, pelo menos da presença literária de outras figuras de igual merecimento como, por exemplo, José de Alencar.

Machado participava dos acontecimentos.

- Graça a trabalhos, entre os quais o do acadêmico Raimundo Magalhães Júnior, conhecemos melhor a pessoa, a sua vida interior, o seu procedimento social e cívico. Não era o casmurro distante, metido consigo mesmo, indiferente aos acontecimentos políticos como foi pintado. Tinha sensibilidade patriótica, ideias cívicas e algumas vezes bateu-se por elas. Tudo, naturalmente, com a medida e o recato do seu temperamento. Foi, assim, um cidadão, isto é, um homem que compartilhou das inquietações, dos interesses, da vida do seu país, que opinou e escolheu as correntes em conflito. A Guerra do Paraguai, a Abolição, a República foram os grandes movimentos que se operaram no seu tempo. A respeito de todos, Machado pronunciou-se como jornalista e homem público.

Lima Barreto e Machado

Perguntado sobre o que pensava dos romancistas modernos em relação a Machado, respondeu-nos:

- Acho que os romancistas modernos, um Graciliano, um Lins do Rêgo, um Jorge Amado, um Veríssimo e outros mais recentes são tão importantes para a literatura brasileira, como língua e psicologia, como valores típicos, quanto Machado de Assis. Estão longe dele e descobriram as nossas originalidades autóctones. Não vejo vantagem em escrever como Frei Luís de Sousa, quando se pode tirar da língua portuguesa do Brasil, sem ferila nos seus cânones, todos os efeitos plásticos que a vida moderna exige e comporta. É verdade que ouvi muitas vezes Lima Barreto atacar Machado de Assis e possuo mesmo uma carta em que me agradece muito o fato de haver, em artigo, mostrado como os dois são diferentes. Faltava a Lima a nobreza convencional do estilo e certa isenção criadora, tão vivas na obra de Machado. Acredito, no entanto, que apesar de tudo, Lima Barreto se sentia bastante lisonjeado quando o comparavam com o mestre de Brás Cubas. De quem Lima não gostava mesmo, e injustamente, era de Coelho Neto. 
Os novos e Machado

Uma última observação do Sr. Austregésilo de Ataíde:

- A atitude das futuras gerações diante de Machado? A que se tem em face dos clássicos. Será sempre admirado e querido pelos espíritos mais cultos e apurados, embora deixe de ter a influência direta na evolução literária do Brasil. Creio que Macaulay disse algo semelhante escrevendo a respeito do Dr. Johnson. A espécie de idolatria exclusivista do "machadismo" da minha geração tende a desaparecer.

\section{Referências:}

ACADEMIA BRASILEIRA DE LETRAS. Austregésilo de Athayde: Biografia. Online. Acessível em: <http://www.academia.org.br/academicos/austregesilo-deathayde/biografia $>$ Acesso em: 10.02.2020.

ATHAYDE, Austregésilo de. Austregésilo de Athayde. Seleção e prefácio Murilo Melo Filho. São Paulo: Global, 2008 (Coleção Melhores Crónicas. Direção Edla van Steen.)

SILVA, José Pereira da. A Comissão Machado de Assis e a crítica textual no Brasil. Acessível em: $<$ http://www.filologia.org.br/machado_de_assis/A\%20Comiss\%C3\%A3o\%20 Machado\%20de\%20Assis\%20e\%20a\%20cr\%C3\%ADtica\%20textual\%20no\% 20Brasil.pdf>. Acesso em: 10.02.2020.

MARCELO DIEGO é professor adjunto de Literatura Comparada na Universidade Federal do Rio de Janeiro e membro do Grupo de Pesquisa / CNPq "Ficção de Machado de Assis: sistema poético e contexto".

(Dhttps://orcid.org/0000-0001-8590-5009 E-mail: marcelodiego@letras.ufrj.br 